\title{
Self Medication Practices among Youngsters: A Global Health Concern
}

\author{
Navdeep Kaur ${ }^{1}$, Bandana Bisht ${ }^{2}$, Manmeet Kaur ${ }^{3}$ \\ ${ }^{1}$ Vice Principal, Chitkara University College of Nursing, Chitkara University, Himachal Pradesh, India, \\ ${ }^{2}$ Principal, Chitkara University College of Nursing, Chitkara University, Himachal Pradesh, India, ${ }^{3}$ Assistant \\ Professor, Chitkara School of Health Sciences, Chitkara University, Punjab, India
}

\begin{abstract}
Self medication is considered as key aspect of primary health care to treat minor symptoms. However, inappropriate practice of self medication and related potential dangers has become public health concern worldwide.

Objectives: This study aimed at assessing the prevalence and frequency of practicing self medication. Common self diagnosed Disorders and prime reasons for engaging in self medication were explored by the researchers. Also, association between self medication and various sociodemographic variables was also discovered.

Method: The study employed exploratory design. A self structured questionnaire was administered to 500 students of selected University. The data were summarized and analyzed using descriptive and inferential statistics.

Results: Overall 442 (88.4\%) students practiced self medication and approximately $77 \%$ of study subjects consume self medications occasionally. Headache (84.4\%), common cold (83.8\%), cough (82.6\%) and gastric acidity $(81.8 \%)$ were the most common minor ailments for which self medication is being taken. Major driving factors behind self medication are considering minor ailments non- seriously (83\%), easy availability of medicines (82\%) and lack of trust in institute dispensaries (79\%). Further, no significant association was found between self medication practices and age, gender, year of study, academic disciplines, parents' education level, place of residence. Conclusion: Prevalence of self medication is remarkably high among scholars which constitutes health concern that requires conduction of awareness programs on risk and benefit of self medication at university level and stringent laws on sale of medicines without current prescription needs to be enforced to control malpractice.
\end{abstract}

Keywords: Self medication, Prevalence, malpractice.

\section{Introduction}

Self medication is a process of medicating oneself for self-diagnosed diseases. It involves consuming medicines without physician's advice, taking medicines on advice of pharmacist, relative or friend, using old prescriptions, sharing medicines with others and taking leftover medicines at home. ${ }^{1-4}$ Key drives of self medication are inadequacies in healthcare system especially in developing world such as inaccessibility, inequitable distribution of health, high costs, patient' attitude and lack of healthcare resources. ${ }^{5}$ Though, it provides the patients' greater independence in managing minor ailments, hence enhance empowerment. Also, self medication is advantageous to health care system and people when practiced correctly as it reduces time spent in visiting doctors, decreases load on medical services and saves cost. ${ }^{6}$ Despite these facts, major problem is an inappropriate use of self medication thus resulting in detrimental consequences such as masking of potential health problems, severe adverse effects, and antibiotic resistance. Hence, Self medication has become a widespread practice and is an emerging health issue across the globe especially in developing countries. ${ }^{7,8}$ 
The prevalence of self-medication practice has risen sharply worldwide especially in economically deprived countries owing to limiting health resources. Certain projected evidences shown that prevalence of self medication in developing nations is in the range of $12.7 \%$ to $95 \% .{ }^{9-11}$ Moreover, there are huge variations in practice of self medication among population due to factors such as at age, gender, self care orientation, education level, drug access and exposure to advertisements by pharmaceutical companies. ${ }^{9.10}$ Further, the most common ailments for which self-medication is being practiced are fever, headache, diarrhea, constipation, common cold as reported by many researchers. ${ }^{11}$ Moreover, people do not refrain from consuming antimicrobials for self-care that may lead to serious drug related problems such as antimicrobial resistance and toxicity. ${ }^{12,6}$

Although, many studies are conducted at community level to assess magnitude of self medication, but only few studies are done to estimate prevalence in practicing self medication in youngsters who belong to the most vulnerable population. Through this study, researcher tried to explore the data from students of selected university with aims of find out the prevalence of self medication, common condition for which self medication is being used, and also to identify the association between factors such as age, gender, parent's education level and self medication practices.

\section{Materials and Method}

An exploratory study was conducted in selected university, Punjab, India in March, 2019. The sample size of 500 participants was determined using Power Analysis with formula as $n=z^{2} \mathrm{P}(1-\mathrm{p}) / \mathrm{w}^{2}$ at $5 \%$.Respondents from the available population were chosen with multi-staged cluster sampling. In stage one, five departments were chosen, and 100 students were selected from each of the five departments in second stage using simple random method. Ethical approval was taken from ethical review committee of university. Also, an informed written content of respondents was taken with assurance of anonymity and confidentiality of data. Content validity of self structured tool was assured by five experts from departments specialized in pharmacy, nursing, health sciences and further data was collected using a pretested self administered questionnaire with closed and open ended questions. The respondents who were practicing self medication had to select/write the ailments for which they self medicate and the reason for such behavior. Finally, collected data was checked for completeness and analysis was done using SPSS latest version 25 .

\section{Results}

The sociodemographic characteristics of the respondents depicts that most of them were females $(55.9 \%)$ and hostellers ((52.8\%). Majority of study subjects were from age group 19-20 years $(65.6 \%)$ and having parental education level up to graduation and above (mother $-71.6 \%$, father- $78.8 \%$ ) as shown in table 1. Approximately $88 \%$ of the respondents admitted to self medication practice and majority of subjects $77.3 \%$ used self medication for treating minor illnesses occasionally as depicted in figure 1 and 2 respectively. Most common ailment for self medication is pain $(84.40 \%)$, followed by respiratory problems $(83.8 \%)$, gastrointestinal problems $(81.8 \%)$ and other health problems $(83.2 \%)$ as seen in table 2. Further, in pain, majority of respondents consume self medication for headache $(84.8 \%)$, cold $(83.8 \%)$ is the common respiratory condition for which self medication is being practiced whereas acidity $(81.80 \%)$ and fever $(83.2 \%)$ is the most common ailment in gastrointestinal and other problem for self medication respectively. Most common determinants that lead to self medication among youngsters were non- seriousness of illness (83.4\%), easy availability of drugs (82\%), lack of trust in institute dispensary $(79.2 \%)$, Previous Prescriptions (74\%), convenience (39\%) and costly medicines prescribed by doctors (33\%, table 3$)$. Self medication practice was found not to be significantly associated with any of the sociodemographic variables.

Table No. 1: Frequency and percentage distribution of socio-demographic variables. $N=500$

\begin{tabular}{|l|c|c|c|}
\hline Variables & Opts & Percentage Distribution (\%) & Frequency (f) \\
\hline \multirow{4}{*}{ Age (in years) } & 19 to 20 & $65.6 \%$ & 328 \\
\cline { 2 - 4 } & 21 to 22 & $33.4 \%$ & 167 \\
\cline { 2 - 4 } & 23 to 24 & $1.0 \%$ & 5 \\
\cline { 2 - 4 } & 24 to 25 & $0.0 \%$ & 0 \\
\hline
\end{tabular}




\begin{tabular}{|l|c|c|c|}
\hline Variables & Opts & Percentage Distribution (\%) & Frequency (f) \\
\hline \multirow{4}{*}{ Gender } & Male & $44.2 \%$ & 221 \\
\hline \multirow{4}{*}{ Educational Status of Mother } & Female & $55.8 \%$ & 279 \\
\cline { 2 - 4 } & Primary & $1.4 \%$ & 7 \\
\cline { 2 - 4 } & Metric & $13.6 \%$ & 68 \\
\cline { 2 - 4 } & Senior Secondary & $13.4 \%$ & 67 \\
\hline \multirow{4}{*}{ Educational Status of Father } & Graduation and above & $71.6 \%$ & 358 \\
\cline { 2 - 4 } & Primary & $0.6 \%$ & 3 \\
\cline { 2 - 4 } & Senior Secondary & $4.4 \%$ & 22 \\
\cline { 2 - 4 } & Graduation and above & $8.6 \%$ & 43 \\
\hline \multirow{3}{*}{ Place of Present Stay } & Hostel & $78.8 \%$ & 394 \\
\cline { 2 - 4 } & Home & $52.8 \%$ & 264 \\
\cline { 2 - 4 } & Paying guest (PG) & $45.4 \%$ & 227 \\
\hline
\end{tabular}

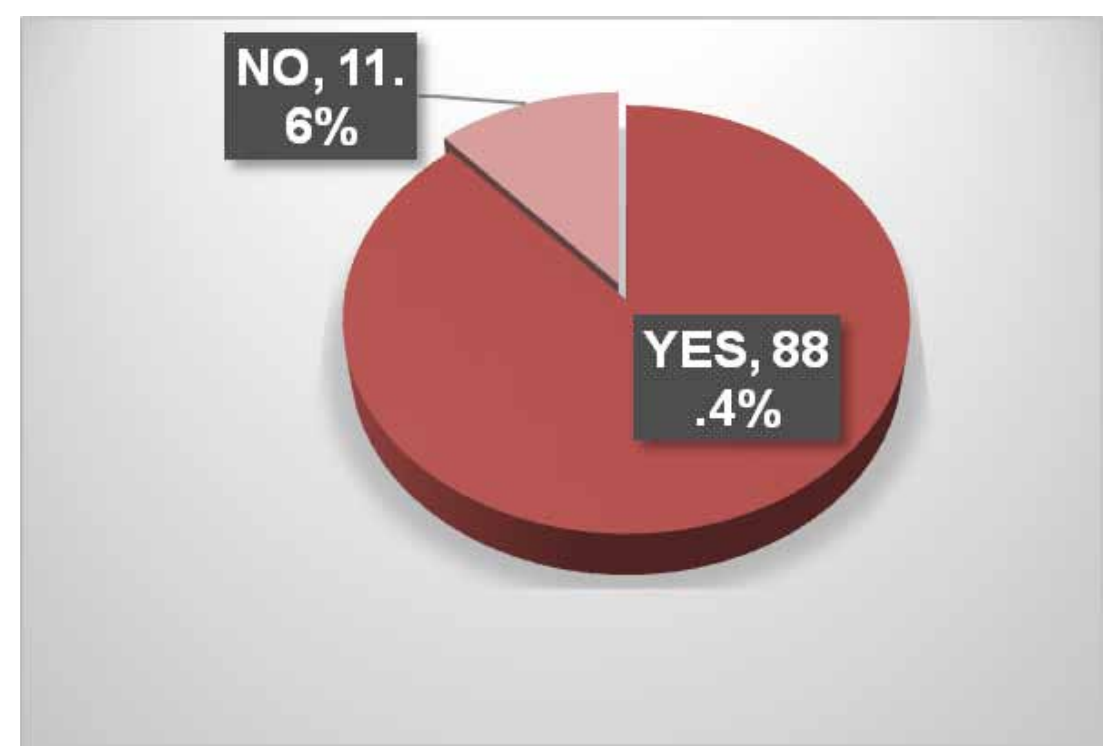

Fig no. 1: Prevalence of self-medication

$100.00 \%$

$90.00 \%$

$80.00 \%$

$70.00 \%$

$60.00 \%$

$50.00 \%$

$40.00 \%$

$30.00 \%$

$20.00 \%$

$10.00 \%$

$0.00 \%$

Fig no. 1: Prevalence of self-medication 
Table 2: Common minor ailments for which self-medication is being used $(\mathrm{N}=442)$

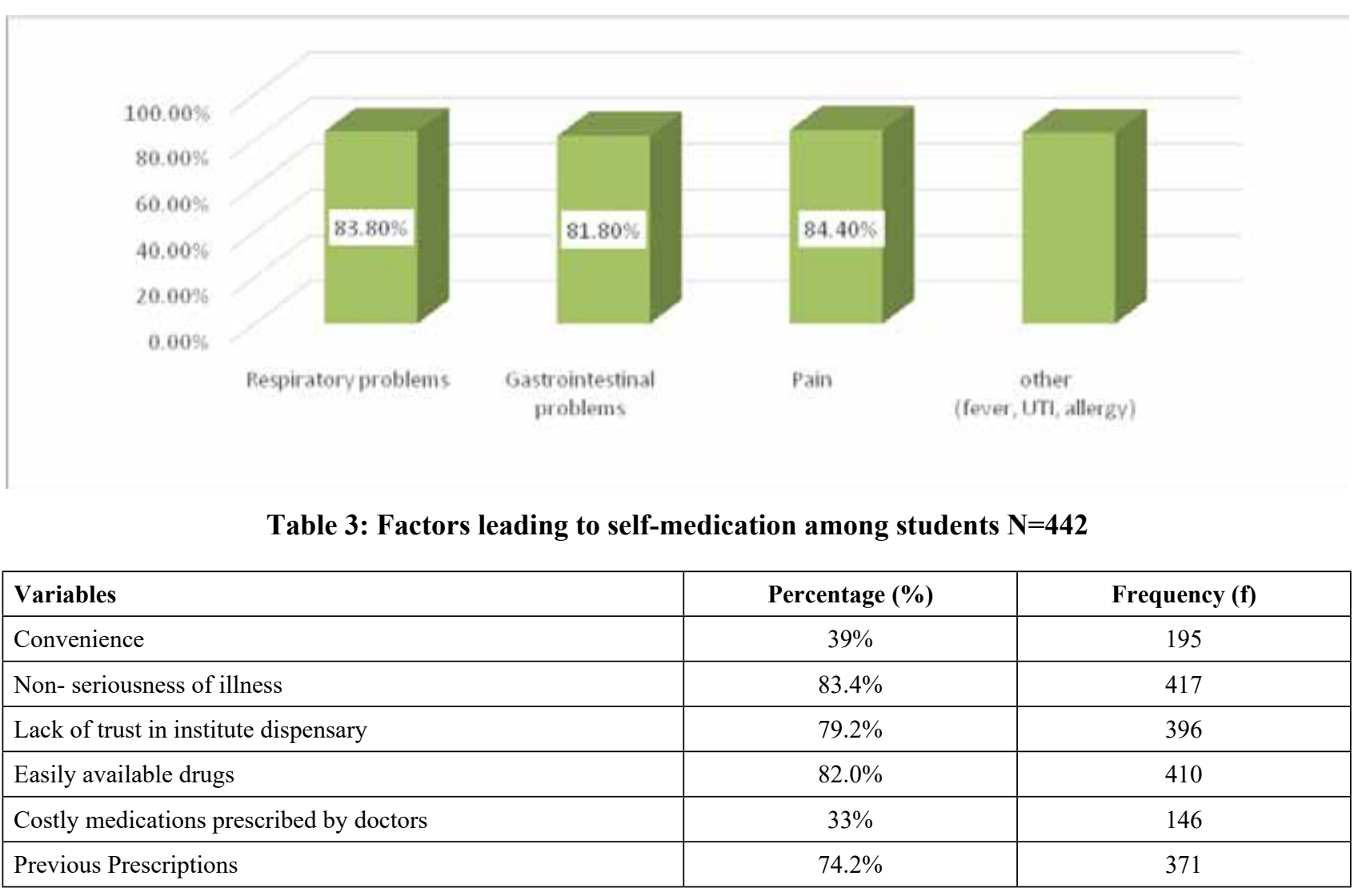

\section{Discussion}

Prevalence of self medication is increasing worldwide particularly among youngsters and university students. ${ }^{13,14}$ Many factors like readily available medicines, lack of accessible health services, extensive advertisement are leading causes of such practice. ${ }^{15,16}$

The findings of this revealed that the prevalence of self-medication is $88 \%$ among the university students and $77.3 \%$ respondents practice self medication now and then. The prevalence is considerable high and similar results were found in students of Bangladesh (100\%), Brazil (86.4\%), South India (92\%) and Southwest Nigeria (91.4\%). ${ }^{17,20}$ However, lower prevalence of self medication was reported by few studies as many university students declared not to self medicate. ${ }^{21,22}$ In few, this difference could be attributed to the drug laws of country, accessibility to quality health services and discipline of the students

The results of this study reported that most common health problem that encouraged self-medication practice was pain (headache), followed by respiratory problems like cold, cough, then gastrointestinal problems such as acidity and, lastly for fever, UTI and allergies. Similarly, some studies reported comparable observations in which headache, common cold and fever were leading ailments for such practice ${ }^{23,11}$ where studies conducted in Egypt and western Nigeria found sore throat, intestinal colic, cramps and urinary tract infection, diarrhea as main complaints that lead to self medication respectively. ${ }^{24,25}$ These variations in findings could be because of different study population in all studies.

In the current study, causative factors for self medication practice among university students were non- seriousness of illness (83.4\%), easy availability of drugs (82\%), lack of trust in institute dispensary (79.2\%) using previous prescriptions (74\%). Various studies revealed many different reasons for indulging into self medication. ${ }^{20,26,27}$ These reasons can be attributed to the fact the practice of self medication is influenced by several factors such as family, advertising, having previous experience, financial constraints. Not only this, seeking advice from pharmacists and friends to overcome the obstacles related to medical care cost and 
dissatisfaction with medical care, lead to irrational self medication.

In present study, no association was found between selfmedication practice and sociodemographic variables. On the contrary, previous studies found that females tend to self medicate more as compare to males and this gender difference could be related to special health conditions in women like menstruation. ${ }^{28}$ In addition to this, self medication is more common in residents of urban as per former studies. Reason for such variation can be described by difference in accessibility of health services. ${ }^{24}$

\section{Conclusion}

This study concluded that majority of university students engaged into self medication practice, and headache, cold, gastric acidity are the minor diseases for which self medication is being practiced. Further, non- seriousness about mild- illness, availability of drugs, lack of trust in institute dispensary and previous knowledge about disease were the main driving forces for indulging into self medication. Self medication, when used appropriately may not be harmful, but, it's inappropriate use poses a threat. So, awareness programs must be inculcated at university level to enlighten the youth about benefits and risks of self medication.

Limitations: One of the limitations is that analysis of this study was based on self report with chances of over and under reporting. Also, results of current study cannot be generalized to students of other universities of state and nation.

Conflicts of Interest: The researchers, hereby, declare there are no conflicts of interest related with present study or with materials and procedures used in this study.

Ethical Clearance: Ethical approval was taken from institutional ethical committee.

\section{Funding: No}

\section{References}

1. Selvaraj K, Kumar GS, Ramalingam A. Prevalence of self-medication practices and its associated factors in Urban Puducherry. Perspect Clin Res. 2014 Jan-Mar; 5(1): 32-36.

2. Esan D T, Fasoro AA, Odesanya OE, Esan TO, Ojo EF, Faeji CO. Assessment of Self-Medication
Practices and Its Associated Factors among Undergraduates of a Private University in Nigeria. Journal of Environmental and Public Health Volume; 2018, Article ID 5439079, 7 pages https:// doi.org/10.1155/2018/5439079

3. C. M. Hughes, J. C. McElnay, and G. F. Fleming, "Benefits and risks of self medication," Drug Safety 2001; 24(14):1027-1037.

4. Z. Klemenc-Ketis, Z. Hladnik, and J. Kersnik. Selfmedication among healthcare and non-healthcare students at university of Ljubljana, Slovenia. Medical Principles and Practice 2010;19(5):395401.

5. Bakri A, Bustanji, \& Wazaify. Factors contributing to problems with medication use. .Social and administration aspects of pharmacy in low-middle income countries; 2008: 249.

6. Ruiz ME. Risks of Self-Medication Practices. Curr Drug Saf 2010 Oct; 5(4):315-23.

7. H. Bauchner and P. H. Wise. Antibiotics without prescription: bacterial or medical resistance. The Lancet 2000;355: 1480-1484.

8. P. Calabresi and L. M. Cupini. Medication-overuse headache: similarities with drug addiction. Trends in Pharmacological Sciences 2005; 26(2):62-68.

9. Klemenc-Ketis Z., Hladnik Z., Kersnik J. Selfmedication among healthcare and non-healthcare students at University of Ljubljana, Slovenia. Medical Principles and Practice. 2010;19 (5):395401.

10. Bennadi D. Self-medication: a current challenge. Journal of Basic and Clinical Pharmacy. 2014; 5 (1):19-23.

11. Abay SM, Amelo W. Assessment of self-medication practices among medical, pharmacy, and health science students in Gondar University, Ethiopia. J Young Pharm. 2010; 2:306-10.

12. Loyola Filho AI, Lima-Costa MF, Uchôa E. Bambuí project: A qualitative approach to self-medication. Cad Saude Publica. 2004; 20:1661-9.

13. G. B. Gutema, D. A. Gadisa, Z. A. Kidanemariam et al. Self-medication practices among health sciences students: the case of Mekelle University. Journal of Applied Pharmaceutical Science 2011; 1 (10): 183-189.

14. H. James, S. S. Handu, K. A. J. Al Khaja, S. Otoom, 
and R. P. Sequeira. Evaluation of the knowledge, attitude and practice of self-medication among first-year medical students. Medical Principles and Practice 2006; 15(4): 270-275.

15. D. Galato, L. D. M. Galafassi, G. M. Alano, and S. C. Trauthman. Responsible self-medication: review of the process of pharmaceutical attendance. Brazilian Journal of Pharmaceutical Sciences 2009; 45(4): 625-633.

16. Hussain A and Khanum A. Self-medication among university students of Islamabad, Pakistan-a preliminary study. Southern Med Review 2008. 1(1): 14-16.

17. N. Alam, N. Saffoon, and Uddin R. Selfmedication among medical and pharmacy students in Bangladesh. BMC Research Notes 2015; 8 (1): 763.

18. M. G. Corrêa da Silva, M. C. F. Soares, and A. L. Muccillo-Baisch. Self-medication in university students from the city of Rio Grande, Brazil. BMC Public Health 2012; 12 (1): 339.

19. K. P. Osemene and A. Lamikanra. A study of the prevalence of self-medication practice among university students in southwestern Nigeria. Tropical Journal of Pharmaceutical Research 2012; 11(4): 683-689.

20. S. Badiger, R. Kundapur, A. Jain et al. Selfmedication patterns among medical students in South India. Australasian Medical Journal 2012; 5 (4) :217-220.

21. De Aquino D S, De Barros J A C, and Da Silva
M D P. Self-medication and health academic staff. Ciencia e SaudeColetiva 2010; 15 (5): 2533-2538.

22. C. Buke, M. Hosgor-Limoncu, S. Ermertcan et al. Irrational use of antibiotics among university students. Journal of Infection 2005; 51 (2):135139.

23. Kumar N, Kanchan T, Unnikrishnan B, Rekha T, Mithra P, Kulkarni V, et al. Perception and practices of self-medication among medical students in costal South India. PLoS One. 2013; 8(8):e72247.

24. R.M. Helal and H.S. Abou-Elwafa. Self-medication in University students from the city of Mansoura, Egypt. Journal of Environmental and Public health 2017; 10:1-7.

25. R. K. Verma, L. Mohan, and M. Pandey. Evaluation of self-medication among professional students in North India: proper statutory drug control must be implemented. Asian Journal of Pharmaceutical and Clinical Research 2010; 3(1): 60-64,

26. D. D. Goel. Self-medication patterns among nursing students in North India. IOSR Journal of Dental and Medical Sciences 2013. 11(4). 14-17.

27. A. Auta, D. Shalkur, S. Omale, and A. H. Abiodun. Medicine knowledge and self-medication practice among students. African Journal of Pharmaceutical Research and Development 2012; 4 (1): 6-11.

28. Lukovic JA, Miletic V, Pekmezovic T, Trajkovic G, Ratkcovic N, Aleksic D, Grgurevic A. Selfmedication practices and risk factors for selfmedication among medical students in Belgrade, Serbia. PLoS One. 2014; 9(12):e114644. 